\title{
A Systematic Study of the Effect of Silver on the Chelation of Formic Acid to a Titanium Precursor and the Resulting Effect on the Anatase to Rutile Transformation of TiO2
}

\author{
Nicholas Nolan \\ Technological University Dublin, nicholas.nolan@tudublin.ie \\ Michael Seery \\ Technological University Dublin, michael.seery@tudublin.ie \\ Steve Hinder \\ University of Surrey, S.Hinder@surrey.ac.uk
}

See next page for additional authors

Follow this and additional works at: https://arrow.tudublin.ie/cenresart

Part of the Materials Chemistry Commons, and the Physical Chemistry Commons

\section{Recommended Citation \\ Nolan, N. et al. (2010) :A Systematic Study of the Effect of Silver on the Chelation of Formic Acid to a Titanium Precursor and the Resulting Effect on the Anatase to Rutile Transformation of TiO2. Journal of Physical Chemistry C, 114, 2010, pp. 13026 - 13034. doi:10.1021/jp1016054}

This Article is brought to you for free and open access by the Crest: Centre for Research in Engineering Surface Technology at ARROW@TU Dublin. It has been accepted for inclusion in Articles by an authorized administrator of ARROW@TU Dublin. For more information, please contact arrow.admin@tudublin.ie, aisling.coyne@tudublin.ie,gerard.connolly@tudublin.ie. Funder: Environmental Protection Agency, Ireland

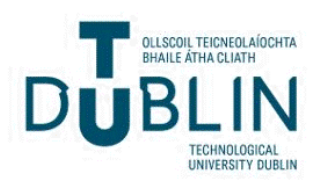


Authors

Nicholas Nolan, Michael Seery, Steve Hinder, Linda Healy, and Suresh Pillai

This article is available at ARROW@TU Dublin: https://arrow.tudublin.ie/cenresart/11 


\title{
1 A Systematic Study of the Effect of Silver on the Chelation of Formic Acid to a Titanium 2 Precursor and the Resulting Effect on the Anatase to Rutile Transformation of $\mathrm{TiO}_{2}$
}

\author{
Nicholas T. Nolan, ${ }^{\dagger,}{ }^{\dagger}$ Michael K. Seery, ${ }^{*},{ }^{\dagger}$ Steven J. Hinder, ${ }^{\S}$ Linda F. Healy, ${ }^{\dagger}$ and \\ Suresh C. Pillai*,§ \\ School of Chemical and Pharmaceutical Sciences, Dublin Institute of Technology, Kevin Street, \\ Dublin 8, Ireland, Centre for Research in Engineering Surface Technology, Focas Institute, Dublin Institute of \\ Technology, Kevin Street, Dublin 8, Ireland, and The Surface Analysis Laboratory, Faculty of Engineering and \\ Physical Sciences, University of Surrey, GU2 7XH, United Kingdom
}

Received: February 23, 2010; Revised Manuscript Received: May 17, 2010

\begin{abstract}
Anatase to rutile transition in an unmodified synthetic titania usually occurs at a temperature range of 600-700 ${ }^{\circ} \mathrm{C}$. Various methods such as addition of metallic and nonmetallic dopants and modifying the precursor have previously been reported to influence the anatase to rutile transition temperature. In the current study, the effect of addition of increasing amounts of silver to the extent of chelation of a formate group to a titanium precursor and the resulting effects on the transformation of anatase to rutile has been studied. The addition of silver $(0,1,3$, and $5 \mathrm{~mol} \%)$ on the anatase to rutile transformation temperature has been systematically followed by Fourier transform infrared (FTIR), Raman, X-ray diffraction (XRD), differential scanning calorimetry, and X-ray photoelectron spectroscopy (XPS) studies. From the FTIR and Raman spectroscopy studies it was observed that the incorporation of silver caused a reduction in the intensity of the $\mathrm{COO}^{-}$stretches indicating that the titania formate bridging complex is becoming weaker in the presence of silver. XRD studies indicated an early rutile formation for the silver-doped samples. XRD of the samples calcined at 700 ${ }^{\circ} \mathrm{C}$ showed that $5 \mathrm{~mol} \% \mathrm{Ag} \mathrm{TiO}_{2}$ contained both anatase $(46 \%)$ and rutile $(54 \%)$, whereas the undoped sample primarily consists of anatase $(95 \%)$. At $800{ }^{\circ} \mathrm{C}$ all silver doped samples converted to $100 \%$ rutile and the undoped $\mathrm{TiO}_{2}$ consisted of both anatase (55\%) and rutile (45\%). XPS analysis showed that $\mathrm{Ag}^{0}$ and $\mathrm{Ag}_{2} \mathrm{O}$ has been formed on the surface of the titania formate complex without calcination $\left(>100{ }^{\circ} \mathrm{C}\right)$ indicating that photo-oxidation has occurred. FTIR, Raman, and XPS studies confirmed that the presence of silver in the xerogel before calcination may be responsible for the reduction of the titanium formate bridge. It was concluded that the presence of silver $\left(\mathrm{Ag}_{2} \mathrm{O}\right.$ and $\left.\mathrm{Ag}^{0}\right)$ hindered bridging ligands, which resulted in a weakened titanium gel network. This structurally weakened gel network could easily be collapsed during calcination, and it favors an early rutile formation.
\end{abstract}

\section{Introduction}

Titanium dioxide semiconductor photocatalysis has attracted the attention of several researchers in the past decade due to its environmental applications such as air purification and water remediation. $^{1-10}$ Anatase, rutile, and brookite are the three polymorphs of $\mathrm{TiO}_{2}$ and differ only in arrangement of their $\left[\mathrm{TiO}_{6}\right]^{2-}$ octahedra; anatase (tetragonal) consists of octahedrals sharing vertices; rutile (tetragonal) is connected by edges, and in brookite (orthorhombic) both edges and vertices are connected. ${ }^{11-13}$ Rutile is found freely in nature, but all three can be synthetically prepared. Rutile is the thermodynamically stable phase, while anatase and brookite are both metastable, transferring to rutile under heat treatment at temperatures typically ranging between $600-700{ }^{\circ} \mathrm{C} .{ }^{11}$ Anatase is widely regarded as the most photocatalytically active of the three crystalline structures. ${ }^{13-15}$ Titanium dioxide is the most widely investigated photocatalyst because of its ease of preparation, availability, strong oxidizing power, nontoxicity, and long-term

* To whom correspondence should be addressed. E-mail: michael.seery @ dit.ie (M.K.S.); suresh.pillai@dit.ie (S.C.P.).

School of Chemical and Pharmaceutical Sciences, Dublin Institute of Technology.

\$CREST, Dublin Institute of Technology.

${ }^{\S}$ School of Engineering, University of Surrey. stability. ${ }^{7,16}$ However, because of its large band gap (3.2 eV for anatase), $\mathrm{TiO}_{2}$ can only be activated upon irradiation with a photon of light $<390 \mathrm{~nm}$, limiting its use under solar irradiation. ${ }^{16-18}$ Because of this, researchers have been focusing their attention on ways to improve the photocatalytic efficiency of $\mathrm{TiO}_{2}$ under irradiation with visible light $(>400 \mathrm{~nm})$.

Asahi et al. have reported nitrogen doped $\mathrm{TiO}_{2}$ promoting photocatalytic activity up to $\lambda=520 \mathrm{~nm}$ claiming that the presence of nitrogen narrows the band gap of $\mathrm{TiO}_{2}$ thus making it capable of performing visible light driven photocatalysis. ${ }^{19}$ However, Ihara et al. suggested that it is the oxygen vacancies that contributed to the visible light activity, and the doped nitrogen only enhanced the stabilization of these oxygen vacancies. ${ }^{20}$ They also confirmed this role of oxygen vacancies in plasma-treated $\mathrm{TiO}_{2}$ photocatalysts. ${ }^{20}$ In addition the structural oxygen vacancies causing visible light photocatalytic activity was also reported by Martyanov et al. ${ }^{21}$ Further studies with nonmetal dopants, $\mathrm{S},{ }^{22} \mathrm{C},{ }^{23} \mathrm{I},{ }^{24} \mathrm{Br}$, and $\mathrm{Cl},{ }^{18}$ also show red shifts in band gap edge of $\mathrm{TiO}_{2}$.

Transition metal doping has also given promising results for visible light activated $\mathrm{TiO}_{2}$ by extending the absorption spectra into the visible region. Much research has focused on the transition metal ion $\mathrm{Fe}^{3+25-29}$ whereby its incorporation into the crystal lattice results in the formation of new energy levels 
between the valence band and the conduction band ${ }^{30}$ Deposition of noble metals $\mathrm{Ag}, \mathrm{Au}, \mathrm{Pt}$, and $\mathrm{Pd}$ on the surface of $\mathrm{TiO}_{2}$ enhance the photocatalytic efficiency by acting as an electron trap, promoting interfacial charge transfer and therefore delaying recombination of the electron-hole pair..$^{27,31-34}$

Many researchers have focused on modifying $\mathrm{TiO}_{2}$ with $\mathrm{Ag}$. For example, Chao et al. reported the effect of $\mathrm{Ag}$ doping on the phase transformation and grain growth of sol-gel $\mathrm{TiO}_{2}$ powder. ${ }^{35}$ Kuo et al. showed through X-ray diffraction (XRD) and X-ray photoelectron spectroscopy (XPS) that silver on $\mathrm{TiO}_{2}$ surface coatings was easily oxidized into silver oxide $\left(\mathrm{Ag}_{2} \mathrm{O}\right)$ and that the addition of silver causes a reduction in photoluminescence (PL) intensity as found by PL spectroscopy. ${ }^{36}$ This group previously showed enhanced visible light photocatalysis with $\mathrm{Ag}$ modified $\mathrm{TiO}_{2}{ }^{37}$ Choi et al. controlled the ratio of anatase and rutile phases through the addition of surfactants. ${ }^{38}$ The effect of precursor chelation on anatase to rutile transition has also been reported previously. Acetic acid, ${ }^{39}$ formic acid, ${ }^{40}$ urea ${ }^{41}$ sulfuric acid, ${ }^{42}$ and ammonium sulfate ${ }^{43}$ have previously been employed to study the effect of a chelating agent on the anatase to rutile transformation in the $\mathrm{TiO}_{2}$ photocatalyst. However, there are no systematic studies on the effect of silver doping on chelation and anatase to rutile transformation.

The current paper reports a systematic study on how the addition of increasing amounts of silver affects the extent of chelation of a formate group to a titanium precursor and how the resulting reduction in formate chelation causes early transformation of anatase to rutile. The effect of the addition of silver on structural changes is investigated by characterizing the sample in its amorphous state (i.e., before it is calcined) with XPS, IR, and Raman studies. XRD was used to determine the crystalline phase of the calcined samples, and differential scanning calorimetry (DSC) was employed to examine the thermal events of the sample through heat treatment. The effect of silver on the electronic transitions of crystalline $\mathrm{TiO}_{2}$ is shown through UV-vis and PL spectroscopy. To the best of the authors' knowledge this is the first paper to report the effect of silver on a titanium formate complex before calcination and the subsequent effects of the presence of silver upon calcination.

\section{Experimental Section}

Titanium tetraisopropoxide (TTIP)(97\%), formic acid (98\%), and silver nitrate (99\%) were purchased from Aldrich and used without further purification. Deionized water was used in all experimental preparations. The samples were prepared by a modified sol-gel route..$^{40}$ Titanium tetraisopropoxide $(36 \mathrm{~mL})$ was added to formic acid $(19 \mathrm{~mL})$ under stirring. Water $(9 \mathrm{~mL})$ was added, and a thick paste was formed. The TTIP, formic acid, and water were used in 1:4:4 molar ratios. The mixture was stirred for $2 \mathrm{~h}$ and filtered, and the filtrate was dried in an oven at $100{ }^{\circ} \mathrm{C}$ for $12 \mathrm{~h}$. To prepare silver doped titania, the above procedure was repeated, including silver nitrate $(1,3$, and $5 \mathrm{~mol} \%$ ) in the water before it was added to the TTIP/ formic acid mixture. The dried powders were calcined at 300 , 500,700 , and $900{ }^{\circ} \mathrm{C}$ for $2 \mathrm{~h}$ at a ramp rate of $3{ }^{\circ} \mathrm{C} / \mathrm{min}$. A Siemens D $500 \mathrm{X}$-ray diffractometer, with a diffraction angle range $2 \Theta=20-80^{\circ}$ using $\mathrm{Cu} \mathrm{K \alpha}$ radiation, was used to collect XRD diffractograms. The mass fraction of rutile $\left(X_{R}\right)$ in the calcined samples was calculated using the Spurr equation ${ }^{44}$ (eq 1)

$$
X_{\mathrm{R}}=\frac{1}{1+0.8\left(I_{\mathrm{A}} / I_{\mathrm{R}}\right)}
$$

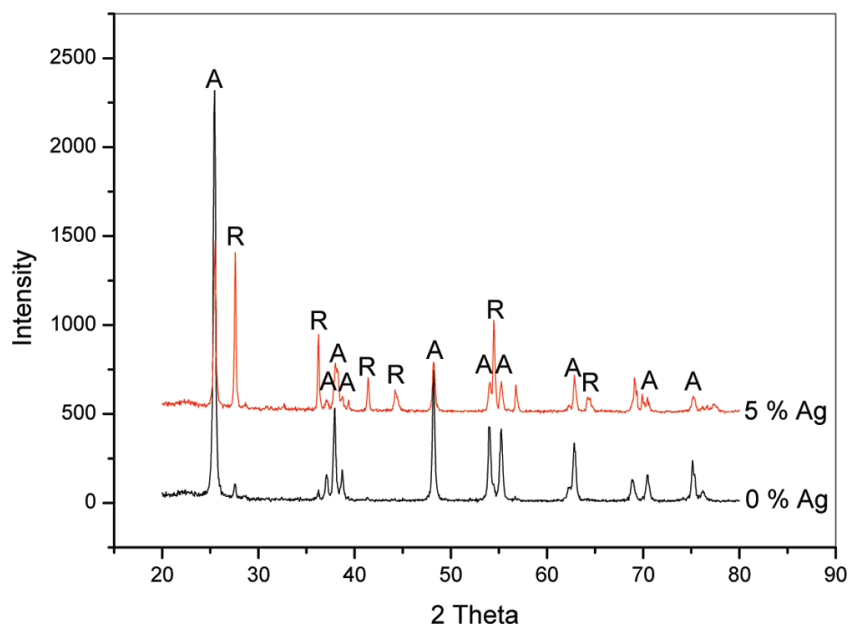

Figure 1. XRD of 0 and $5 \% \mathrm{Ag} \mathrm{TiO}_{2}$ powders calcined at $700{ }^{\circ} \mathrm{C}$.

where $I_{\mathrm{A}}$ is the main intensity of anatase (101) peak and $I_{\mathrm{R}}$ is the main intensity of rutile (110) peak.

The crystallite size $(T)$ was estimated using the Scherrer equation $^{37}$ (eq 2)

$$
T=\frac{0.9 \lambda}{\beta \cos \theta}
$$

where $T$ is the crystalline size, $\lambda$ is the $\mathrm{X}$-ray wavelength, $\theta$ is the Bragg angle, and $\beta$ is the line broadening.

A Perkin-Elmer Lambda 900 UV-vis absorption spectrophotometer was used to record absorption and diffuse reflectance spectra; samples were mixed in $\mathrm{KBr}(1: 20$ sample $\mathrm{KBr})$ and pressed into a tablet; a $\mathrm{KBr}$ tablet made under the same conditions was used as a reference. IR spectra were obtained using a Perkin-Elmer GX FTIR spectrometer and recorded as a $\mathrm{KBr}$ disk (1:10 sample/KBr); Raman spectra were recorded on an ISA Labram, employing an argon laser $(514.5 \mathrm{~nm})$ as an excitation source. PL was recorded on a Perkin-Elmer LS55 luminescence spectrometer using an excitation wavelength of $320 \mathrm{~nm}$. Approximately $5 \mathrm{mg}$ of sample was placed into an aluminum sample pan for DSC using an empty aluminum pan as a reference. All DSC were recorded on a Shimadzu DSC-60 between 25 and $600{ }^{\circ} \mathrm{C}$ at a ramp rate of $20^{\circ} \mathrm{C} / \mathrm{min}$.

\section{Results and Discussion}

XRD. XRD was carried out on the calcined samples in order to determine the crystalline phase of the samples. All samples calcined at $300{ }^{\circ} \mathrm{C}$ were amorphous. Crystalline anatase $\mathrm{TiO}_{2}$ was present for all samples calcined at 500 and $600{ }^{\circ} \mathrm{C}$. However, at $700{ }^{\circ} \mathrm{C}$ the diffractogram (Figure 1) showed that 5 $\mathrm{mol} \% \mathrm{Ag} \mathrm{TiO}{ }_{2}$ contained both anatase (46\%) and rutile (54\%), but $\mathrm{TiO}_{2}$ without silver consisted mainly of anatase $(95 \%)$. This indicated that the presence of increased amounts of silver promotes the anatase to rutile transformation.

Promotion of phase transformation by the addition of silver is believed to be caused by the following factors. ${ }^{35}$ Decreasing anatase grain size (Figure 2) results in an increase in the total boundary energy for the $\mathrm{TiO}_{2}$ powder. The driving force for rutile grain growth is therefore increased, which promotes anatase to rutile phase transformation. ${ }^{45}$ As the transformation of anatase to rutile is a mechanism of nucleation and growth, ${ }^{46,47}$ an increased amount of nucleation sites would favor rutile formation. Phase transformation is also governed by such effects as defect concentration ${ }^{48}$ and grain boundary concentration, ${ }^{49}$ 
Anatase to Rutile Transformation of $\mathrm{TiO}_{2}$

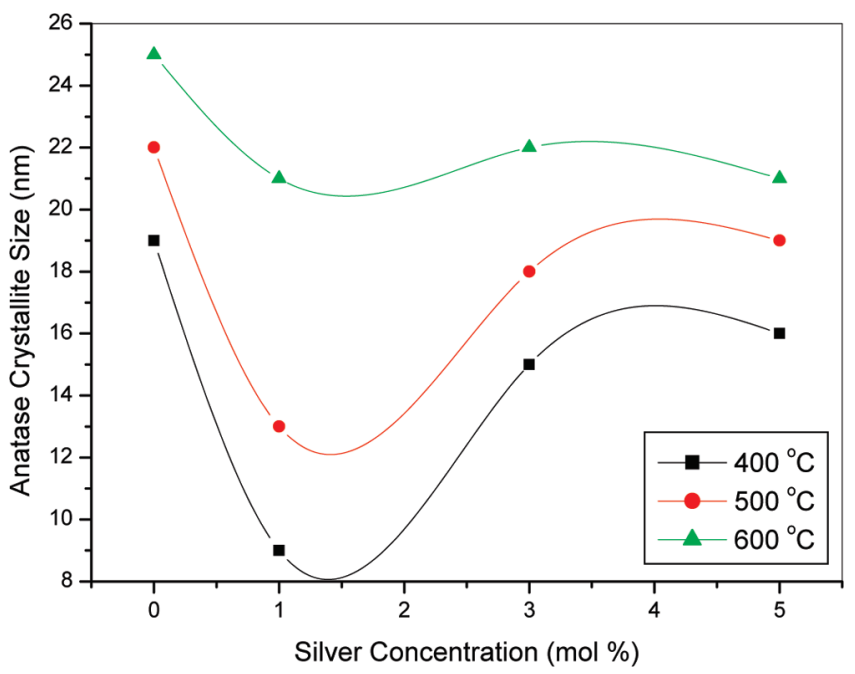

Figure 2. Variation in the nanocrystallite size (from XRD) as a function of increase in concentration of silver, at different calcination temperatures.

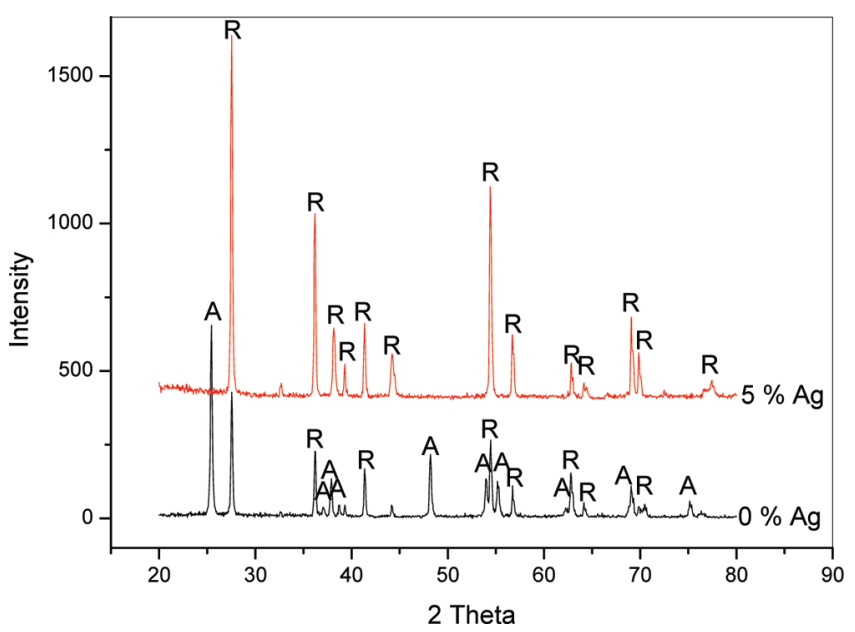

Figure 3. $\mathrm{XRD}$ of 0 and $5 \% \mathrm{Ag} \mathrm{TiO}_{2}$ powders calcined at $800{ }^{\circ} \mathrm{C}$.

the presence of which can be expected to be increased with greater surface areas. Rutile nucleation is thus enhanced as the presence of defect sites is increased. Therefore, an increase in the number of defect sites promotes anatase to rutile transformation at lower temperatures. ${ }^{35}$

At $800{ }^{\circ} \mathrm{C}$, the undoped $\mathrm{TiO}_{2}$ sample consisted of both anatase $(55 \%)$ and rutile $(45 \%)$, whereas the silver-doped samples were all $100 \%$ rutile (Figure 3). A higher Ag concentration promotes earlier phase transformation. Figures 1 and 3 show that the presence of silver promotes the formation of rutile. ${ }^{35}$

The radius of $\mathrm{Ag}^{+}$ion $(126 \mathrm{pm})$ is much larger than that of the $\mathrm{Ti}^{4+}$ ion $(68 \mathrm{pm})$ and so $\mathrm{Ag}^{+}$ions cannot enter the lattice of anatase $\mathrm{TiO}_{2} \cdot{ }^{35,37}$ However, migration of the $\mathrm{Ag}^{+}$ions from bulk anatase grains to the anatase grain surface can occur during calcination. ${ }^{35,37}$ With $\mathrm{Ag}$ migrating to the $\mathrm{TiO}_{2}$ surface, surface defects in the anatase grains will increase. This results in a greater number of nucleation sites for the formation of rutile, again, promoting phase transformation. Oxygen vacancies may also influence the anatase to rutile transformation. ${ }^{35,50,51}$ Previous reports ${ }^{50,51}$ indicate that the concentration of oxygen vacancies at the surface of anatase increases with Ag doping. This favors the ionic rearrangement necessary for the structure changes associated with rutile phase formation. ${ }^{35}$

An alternate effect that the silver may have on early rutile formation is that $\mathrm{Ag}$ cations may be easily reduced. The reduced
J. Phys. Chem. C, Vol. xxx, No. xx, XXXX C

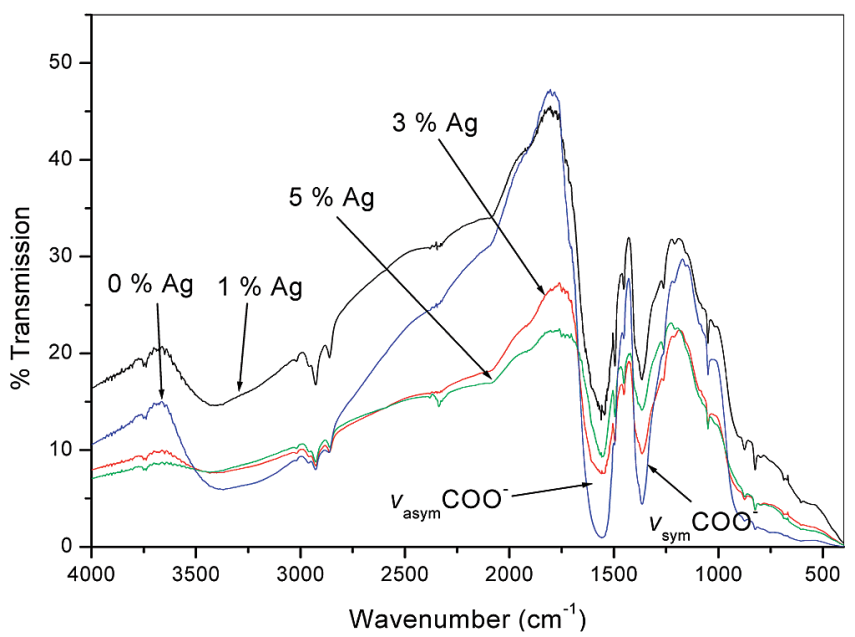

Figure 4. IR spectra of $\mathrm{TiO}_{2}$ powders with different mol \% silver content after aging at $100{ }^{\circ} \mathrm{C}$.

$\mathrm{Ag}^{+}$ions can spread on the anatase surface to $\mathrm{Ag}^{0}$ by heat. Photo reduction of the $\mathrm{Ag}^{+}$ions may also occur as the samples were never protected from light irradiation. ${ }^{52,53}$ Oxygen vacancies will occur for charge compensation caused by $\mathrm{Ag}^{+}$reduction, and again these oxygen vacancies are favored for the formation of rutile. ${ }^{35,50,51}$ To further investigate the role silver plays in altering the transformation temperature of $\mathrm{TiO}_{2}$ in this study, it is necessary to understand the structure of the oligomer before calcination. To gain insight on this, DSC, IR, Raman, and XPS were carried out on the powders before calcination.

IR Spectroscopy. The influence of silver on the structure of the TiO powders was investigated before calcination using IR and Raman spectroscopy. Figure 4 shows IR spectra of the doped and undoped powders. Symmetric and asymmetric $\mathrm{COO}^{-}$ stretches at $\sim 1360$ and $1540 \mathrm{~cm}^{-1}$, respectively, indicated that the formic acid forms a bidentate bridge with the titanium precursor. ${ }^{40,54-56}$

Figure 4 also shows that silver clearly reduces the intensity of the $\mathrm{COO}^{-}$stretches as with each increase in $\mathrm{Ag}$ concentration there is a reduction in intensity of both the asymmetric and symmetric $\mathrm{COO}^{-}$peaks. This result provides evidence for an alternative mechanism to those stated above for early anatase to rutile transformation in the presence of silver. In fact, silver may influence the anatase to rutile transformation through interactions with the titanium precursor in the early stages of the sol-gel synthesis. These interactions may ultimately alter the condensation pathway, resulting in a weakened $\mathrm{TiO}_{2}$ oligomer network.

To compare the effects of aging at $100{ }^{\circ} \mathrm{C}$, IR spectra of samples 0 and $5 \mathrm{~mol} \%$ silver $\mathrm{TiO}_{2}$ were recorded before and after aging (Figures 5 and 6).

After both samples are aged at $100{ }^{\circ} \mathrm{C}$ for $12 \mathrm{~h}$ there is a significant reduction in the bridging formate $\mathrm{COO}^{-}$stretches of the $5 \%$ silver doped sample, whereas the $\mathrm{TiO}_{2}$ sample without silver does not show a significant reduction in the carboxylate stretches. Since the boiling point of formic acid is $101^{\circ} \mathrm{C}$, it is possible that the formic acid is displaced by the presence of silver and is then evaporated upon aging.

Raman Spectroscopy. Raman spectroscopy analysis was carried out on the powders before they were calcined to support IR spectroscopy results.

The Raman spectra of the doped and undoped $\mathrm{TiO}_{2}$ samples, (Figure 7) supports the IR results. As the silver content is increased, the asymmetric and symmetric $\mathrm{COO}^{-}$stretches (1570 and $1390 \mathrm{~cm}^{-1}$ ) decrease accordingly. The addition of silver 


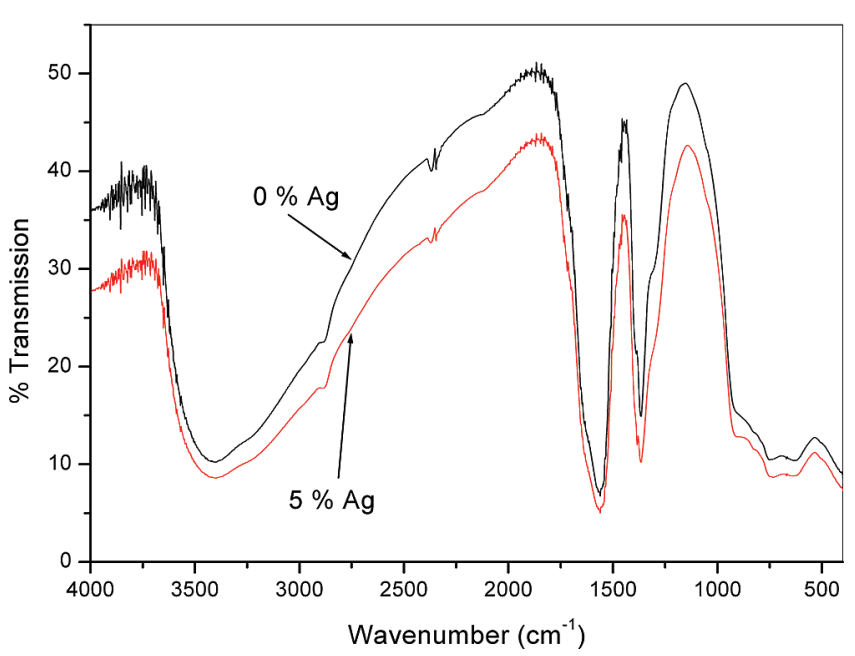

Figure 5. IR spectra of $\mathrm{TiO}_{2}$ powders with different mol $\%$ silver content before aging.

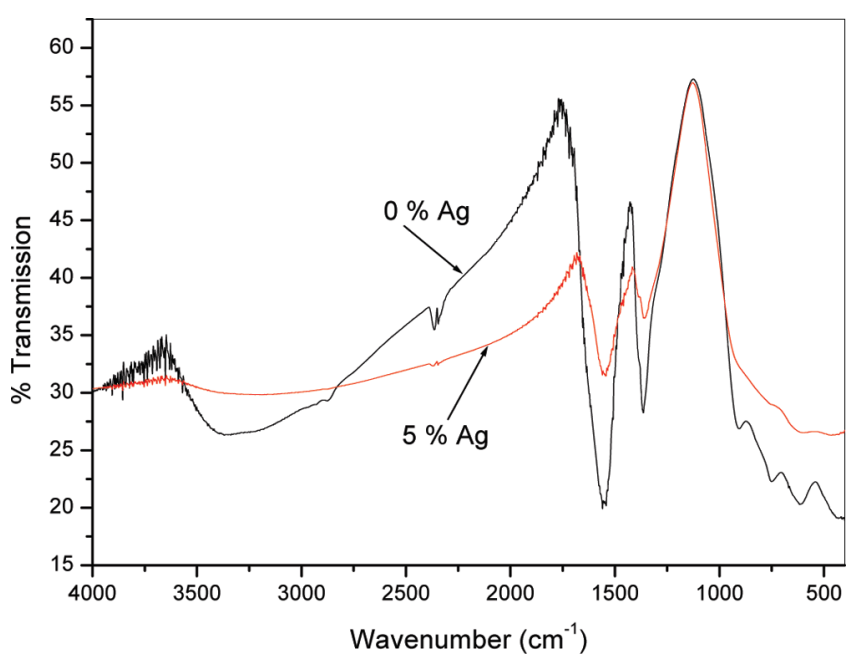

Figure 6. IR spectra of $\mathrm{TiO}_{2}$ powders with different mol \% silver content after aging at $100{ }^{\circ} \mathrm{C}$ for $12 \mathrm{~h}$.

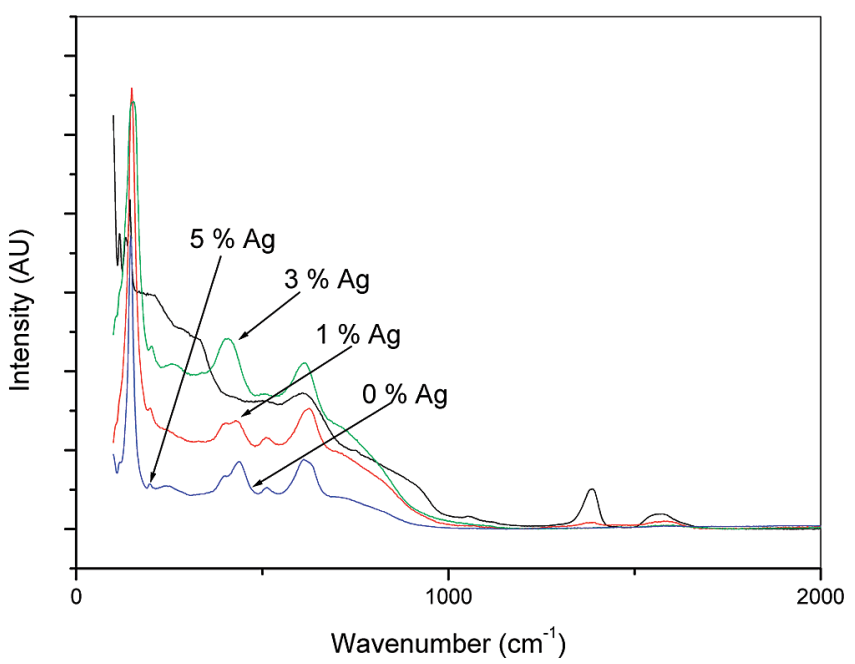

Figure 7. Raman spectra of $\mathrm{TiO}_{2}$ powders with different mol \% silver content before calcination.

also causes significant changes in the $\mathrm{TiO}$ region of the spectra $242\left(0-1000 \mathrm{~cm}^{-1}\right)$. The presence of peaks at $160,420,515$, and 243620 in the Raman of the silver doped $\mathrm{TiO}_{2}$ are indicative of the 244 four peak pattern that would be expected for anatase. ${ }^{57-59}$

245 However, without the presence of silver, this four-peak pattern

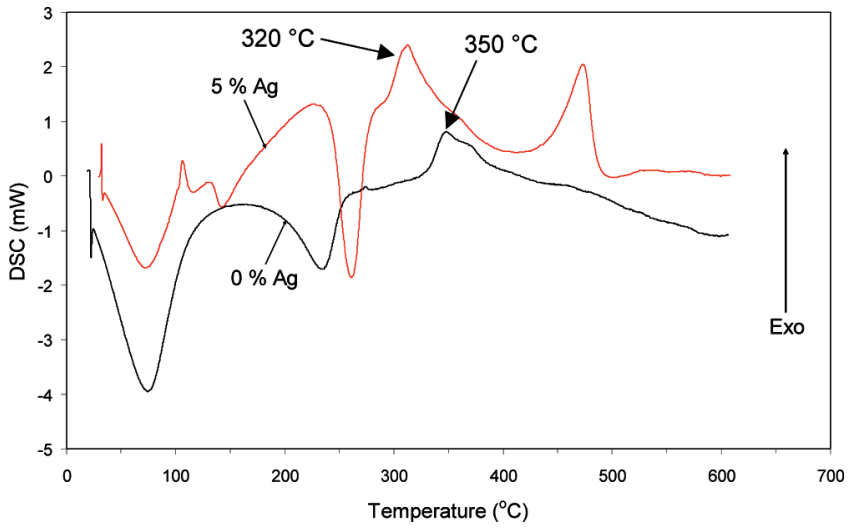

Figure 8. DSC of 0 and $5 \% \mathrm{Ag}$ before aging.

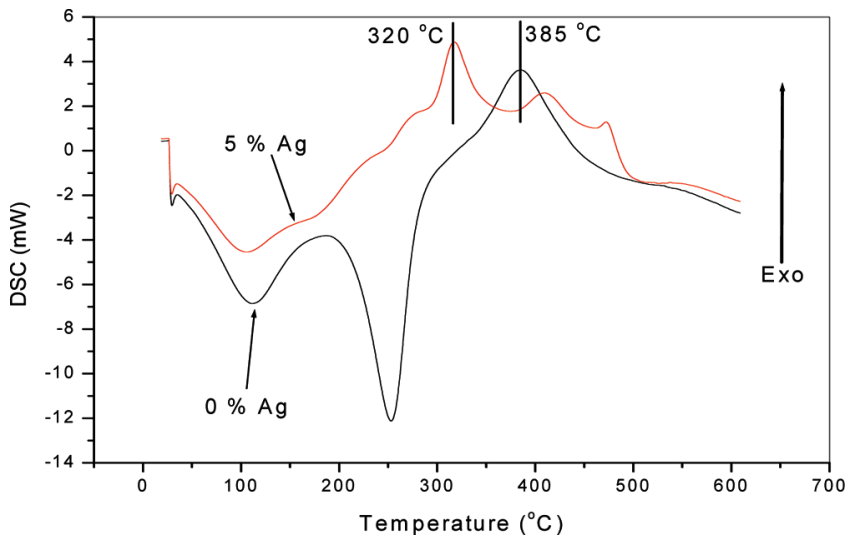

Figure 9. DSC of 0 and $5 \% \mathrm{Ag}$ after aging at $100{ }^{\circ} \mathrm{C}$.

is not as distinctive, again providing further evidence that silver effects the titanium formate complex before crystallization has occurred.

It is agreed that the use of a chelating agent gives stability to the hydrolysis and condensation reactions associated with the sol-gel process in the production of $\mathrm{TiO}_{2}$ from titanium alkoxides..$^{54,60-64}$ IR and Raman spectroscopy have shown that formic acid forms a bridging ligand with titania. ${ }^{55,65-68}$ Previous reports have shown that similar chelating agents remain bound to the central titanium atom, while the isopropoxy (OR) groups are preferentially hydrolyzed. The bridging ligands remain throughout much of the condensation process, ${ }^{54,56}$ altering the condensation pathway and promoting the formation of linear polymers composed of edge sharing octahedral. ${ }^{39,56}$ The system may be destabilized through the addition of water, which leads to a structurally weak network that can easily collapse upon calcination to form rutile. ${ }^{69,70}$

From the spectroscopy results it can be seen that the addition of silver causes a reduction in the intensity of the $\mathrm{COO}^{-}$ stretches indicating that the titania formate bridging complex is becoming weaker in the presence of silver. This may lead to a structurally weak oligomer that upon calcination easily forms rutile at lower temperatures.

DSC. DSC was carried out to investigate the thermal events associated with the doped and undoped $\mathrm{TiO}_{2}$ samples before and after aging.

The DSC curve of the undoped $\mathrm{TiO}_{2}$ powder analyzed before aging (Figure 8 ) is almost identical to the same sample after aging (Figure 9). It reveals an endothermic peak at $\sim 100{ }^{\circ} \mathrm{C}$ attributed to the elimination of unbound water and formic acid from the surface of the $\mathrm{TiO}_{2}$ powder. The same peak for the silver doped sample reveals as expected, a smaller enthalpy of 

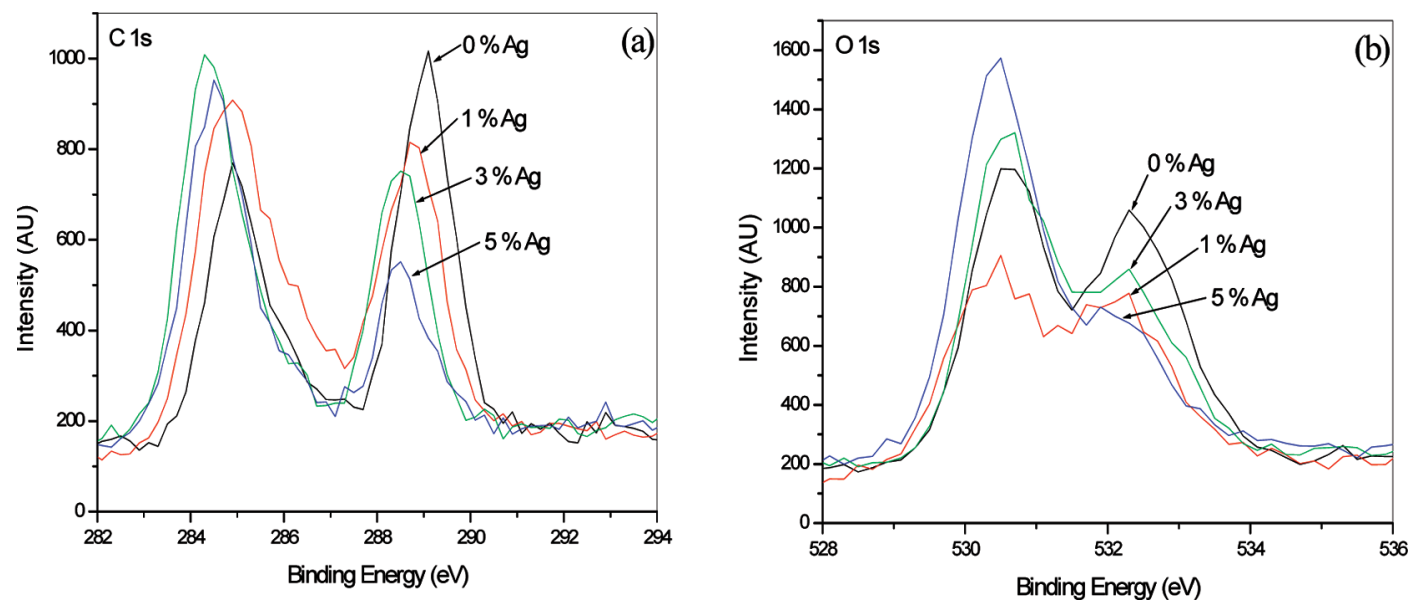

Figure 10. XPS spectra of $\mathrm{C} 1 \mathrm{~s}$ (a) and $\mathrm{O} 1 \mathrm{~s}$ (b) of $\mathrm{TiO}_{2}$ with and without silver before calcination.
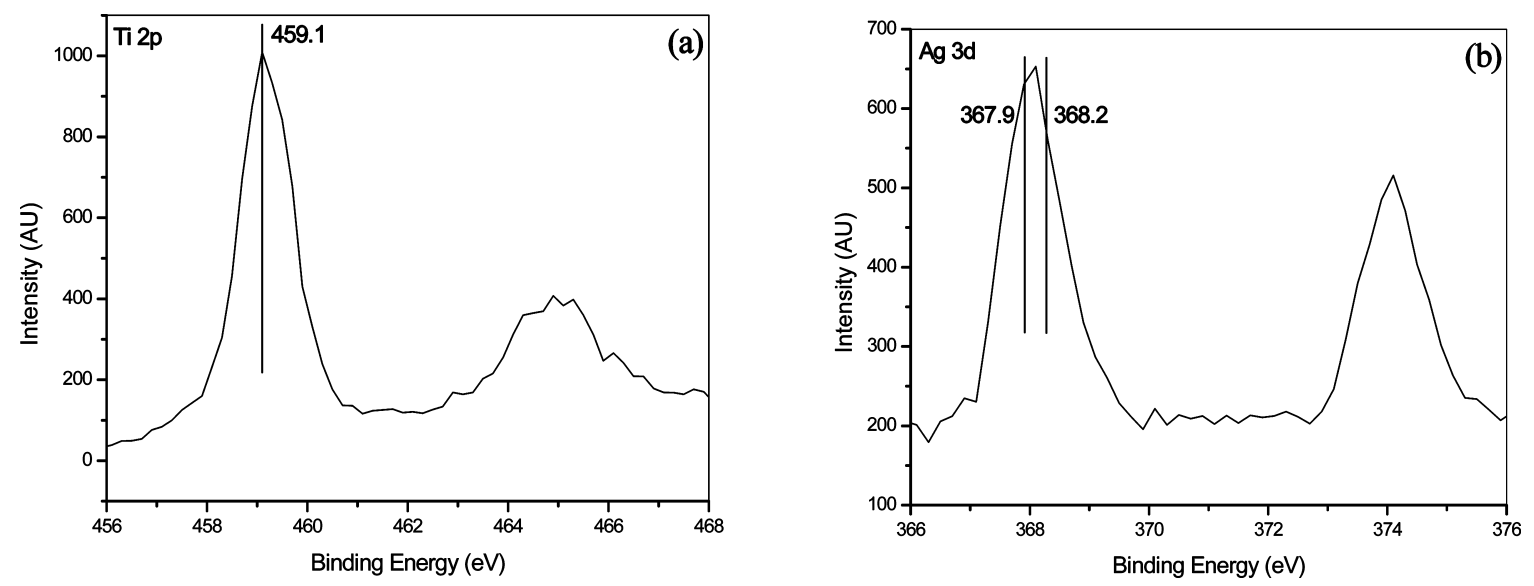

Figure 11. XPS spectra of $\mathrm{Ti} 2 \mathrm{p}$ (a) and $\mathrm{Ag} 3 \mathrm{~d}$ (b) of $3 \% \mathrm{Ag} \mathrm{TiO}_{2}$ before calcination.

$-420 \mathrm{~J} / \mathrm{g}$ compared with $-636 \mathrm{~J} / \mathrm{g}$ for the undoped sample, indicating that formic acid is easier to remove in the presence of silver. This is in agreement with the previously proposed mechanism from the FTIR and Raman spectroscopy results, that silver inhibits formic acid and it is thus removed upon aging at $100{ }^{\circ} \mathrm{C}$ therefore, allowing the oligomer structure to readily collapse and form rutile upon calcination.

In Figures 8 and 9 an endothermic peak at $\sim 250{ }^{\circ} \mathrm{C}$ is due to the removal of isopropanol formed through the condensation step. The removal of isopropanol indicates that the condensation step is complete. Comparing the DSC curves of the samples before (Figure 8) and after (Figure 9) aging shows that the endothermic isopropanol peak is present in both the 0 and 5 mol \% silver sample before aging. But after aging the isopropanol peak at $250{ }^{\circ} \mathrm{C}$ is only present with $0 \% \mathrm{Ag} \mathrm{TiO}_{2}$. This provides further explanation for the formation of rutile at lower temperatures, since when the condensation step is near completion, the crystallization temperature is lowered and then so too is the anatase to rutile transformation temperature.

The appearance of the first exothermic peak in all DSC curves is the transition from amorphous $\mathrm{TiO}_{2}$ to crystalline anatase, and as expected this peak occurs earlier with silver doped $\mathrm{TiO}_{2}$ than with $\mathrm{TiO}_{2}$ only. Figure 8 shows that crystallization occurs at $320{ }^{\circ} \mathrm{C}$ for $5 \% \mathrm{Ag} \mathrm{TiO}$ but does not occur until $350{ }^{\circ} \mathrm{C}$ for the undoped sample. This can also be seen in Figure 9 where crystallization of $5 \% \mathrm{Ag} \mathrm{TiO}_{2}$ takes place at $320{ }^{\circ} \mathrm{C}$ but for the undoped sample crystallization does not occur until $385{ }^{\circ} \mathrm{C}$.

XPS. To determine more information on exactly how the silver is interacting with the titanium formate complex, XPS was carried out on the silver doped and undoped samples before calcination to establish the titanium structure, the chemical state of the silver particles, and also for further evidence of the reduction in the carboxylate species. XPS spectra were recorded of the samples precalcination (as with IR and Raman) and XPS was also carried out on the crystalline titania after calcination. The spectra of $\mathrm{C} 1 \mathrm{~s}$ and $\mathrm{O} 1 \mathrm{~s}$ of $\mathrm{TiO}_{2}$ without silver show the presence of the carboxylate group at $289.1^{71}$ and $532.3 \mathrm{eV},,^{71,72}$ respectively (parts a and $b$ of Figure 10). As the silver content is increased the intensity of these peaks decreases in a similar manner as those of the IR and Raman results, again indicating that with increased silver content, the formation of a titania formate bridging complex becomes increasingly difficult to form.

Figure 11 shows the XPS narrow scans for Ti $2 p$ and Ag $3 d$ peaks. The XPS spectrum of Ti $2 p$ is unchanged with increasing amounts of silver, the $\mathrm{Ag} 3 \mathrm{~d}$ spectrum of $1 \%$ silver $\mathrm{TiO}_{2}$ gives a weaker signal than the $3 \%$ shown in figure $11 \mathrm{~b}$ and the $\mathrm{Ag}$ $3 \mathrm{~d}$ scan of $5 \%$ silver $\mathrm{TiO}_{2}$ results in a spectrum similar to $3 \%$ silver $\mathrm{TiO}_{2}$. The fact that increasing amounts of silver does not affect the Ti $2 p$ spectra indicates that central titanium atom has not been reduced. In Figure 11a, a Ti $2 p$ peak at $459.1 \mathrm{eV}$ is representative of $\mathrm{Ti}$ in its tetravalent state ${ }^{73}$ in an octahedral environment. ${ }^{74}$ The absence of a $\mathrm{Ti}^{3+}$ peak at $457.4 \mathrm{eV}$ leads to the following observations.

(1) $\mathrm{Ti}$ has not been reduced to $\mathrm{Ti}^{3+}$ which may indicate an absence of surface oxygen vacancies. ${ }^{75}$ However, if $\mathrm{TiO}_{n}(n<$ 2 ) is formed it may not be present in detectable amounts. ${ }^{76}$

(2) $\mathrm{Ag}_{2} \mathrm{O}$ or $\mathrm{Ag}^{0}$ incorporation into the $\mathrm{TiO}_{2}$ lattice may give rise to a signal at $457.4 \mathrm{eV}$ representative of $\mathrm{Ti}^{3+} .{ }^{36}$ From the 

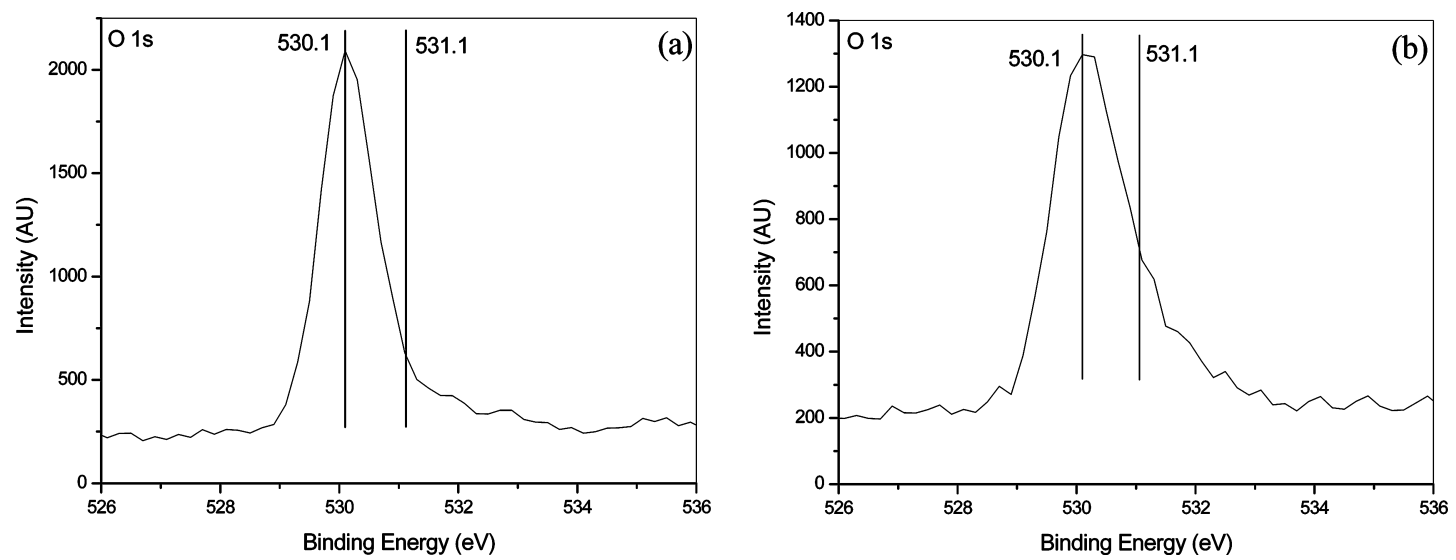

Figure 12. O 1s XPS spectra of $\mathrm{TiO}_{2}$ without silver calcined at $900{ }^{\circ} \mathrm{C}$ (a) and with $3 \%$ silver calcined at $700{ }^{\circ} \mathrm{C}(\mathrm{b})$.
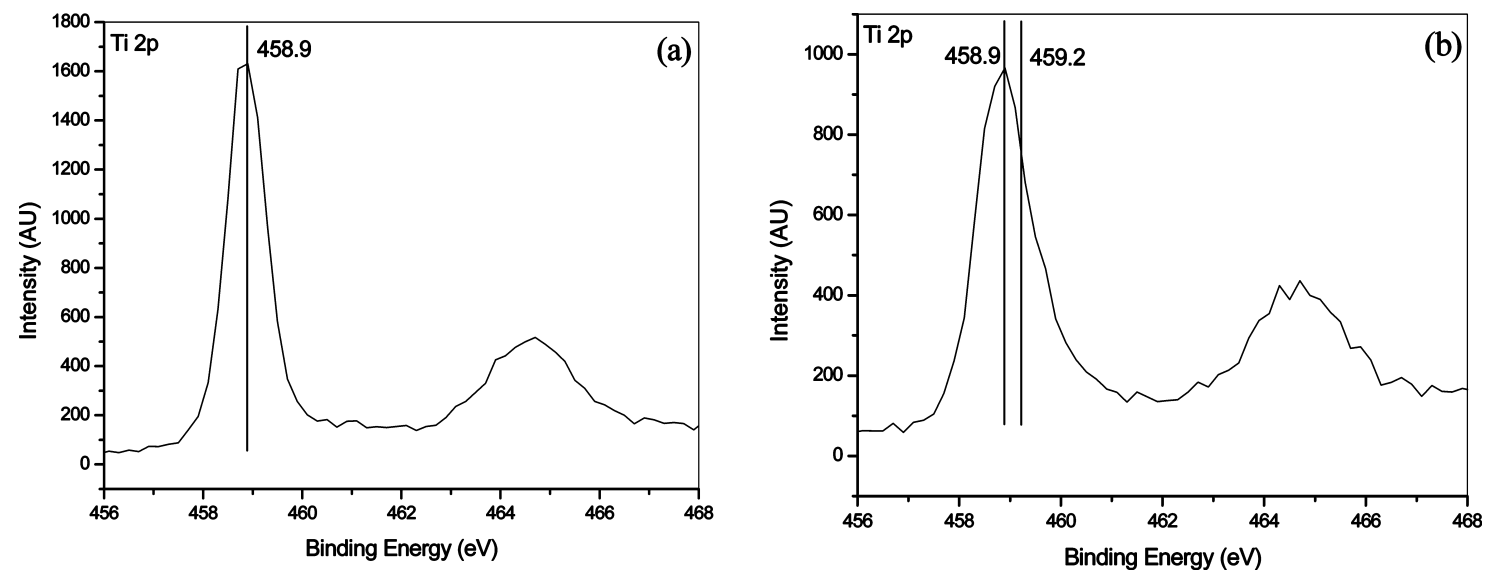

Figure 13. Ti 2p XPS spectra of $\mathrm{TiO}_{2}$ without silver calcined at $900{ }^{\circ} \mathrm{C}$ (a) and with $3 \%$ silver calcined at $700{ }^{\circ} \mathrm{C}$ (b).

XPS there was no evidence of $\mathrm{Ag} \mathrm{TiO}_{2}$ bond formation, which can be expected due to the differences in atomic radius.

The Ag 3d scan (Figure 11b) shows two large peaks. A Gaussian fit of the main peak $(\sim 368 \mathrm{eV})$ showed that it was made up of two signals at 367.9 and $368.2 \mathrm{eV}$, representing the chemical bonding states of $\mathrm{Ag}_{2} \mathrm{O}$ and $\mathrm{Ag}^{0}$, respectively. ${ }^{36}$ Therefore, it has been shown that $\mathrm{Ag}^{0}$ and $\mathrm{Ag}_{2} \mathrm{O}$ have formed on the surface of the titania formate complex, before heat treatment above $100^{\circ} \mathrm{C}$. Spectroscopic (FTIR, Raman, and XPS) studies of the carbonyl species have shown a reduction in the titanium formate bridging complex with increased amounts of silver. The $\mathrm{Ag} 3 \mathrm{~d}$ scan of a sample (before calcination) containing silver (Figure 11b) shows the presence of $\mathrm{Ag}_{2} \mathrm{O}$ $\left(\mathrm{Ag}^{2+}, 367.8 \mathrm{eV}\right)$ and $\mathrm{Ag}^{0}(368.2 \mathrm{eV}) .{ }^{36}$ Therefore, the presence of $\mathrm{Ag}_{2} \mathrm{O}$ and $\mathrm{Ag}^{0}$ in the powders before calcination may be responsible for the reduction of the titanium formate bridge as shown by IR, Raman, and XPS. The presence of $\mathrm{Ag}_{2} \mathrm{O}$ and $\mathrm{Ag}^{0}$ may then restrict the formation of a titanium formate bridging complex which leads to an altered condensation pathway and therefore low temperature formation of rutile.

Figure 12 shows the narrow scan XPS spectra for $\mathrm{O} 1 \mathrm{~s}$ of $\mathrm{TiO}_{2}$ only calcined at $900{ }^{\circ} \mathrm{C}$ and $3 \% \mathrm{Ag} \mathrm{TiO}_{2}$ calcined at 700 ${ }^{\circ} \mathrm{C}$. Gaussian fits of both spectra give rise to two peaks at 530.1 and $531.1 \mathrm{eV}$ for crystal lattice oxygen and hydroxy oxygen, respectively. ${ }^{74,77}$ The silver doped sample contains a greater amount of hydroxy oxygen. Chemisorbed surface hydroxyl groups can enhance photocatalysis by trapping photoinduced holes resulting in an increase in the formation of the highly oxidizing $\mathrm{OH}^{\circ}$ radicals. ${ }^{77,78} \mathrm{It}$ is well reported that silver retards the recombination of photogenerated electron hole pairs, ${ }^{36,37,79}$ this may not only be due to the attraction of excited electrons to silver but also due to the presence of extra hydroxyl species to delay recombination through hole trapping.

There is an apparent difference between the Ti $2 p$ spectra shown in Figure 13. Unmodified $\mathrm{TiO}_{2}$ gives a signal at 458.9 $\mathrm{eV}$ in the $\mathrm{Ti} 2 \mathrm{p}$ narrow scan. However, $3 \%$ silver $\mathrm{TiO}_{2}$ results in the presence of an additional signal at $459.2 \mathrm{eV}$. The undoped sample after calcination at $900{ }^{\circ} \mathrm{C}$ gives a symmetrical peak at $458.9 \mathrm{eV}$ (Figure 13a) typical of tetravalent $\mathrm{Ti}-\mathrm{O}$ bond. ${ }^{73}$ However, the $\mathrm{Ti} 2 \mathrm{p}$ narrow scan of the $3 \% \mathrm{Ag} \mathrm{TiO}_{2}$ sample calcined at $700{ }^{\circ} \mathrm{C}$ does not give a symmetrical peak. A Gaussian fit of the spectrum gives two signals at 458.9 and $459.2 \mathrm{eV}$ both representing $\mathrm{Ti}-\mathrm{O},{ }^{73}$ but the shift in the binding energy to $459.2 \mathrm{eV}$ indicates that there may be an interaction between $\mathrm{TiO}_{2}$ and silver. ${ }^{80}$

Through XPS, IR, and Raman it was shown that the addition of silver restricts the formation of a titanium formate bridging complex. XPS also shows that silver exists as both $\mathrm{Ag}^{0}$ and $\mathrm{Ag}_{2} \mathrm{O}$. Finally, XPS has shown that the presence of silver results in a peak being present at $459.2 \mathrm{eV}$ in the $\mathrm{Ti} 2 \mathrm{p}$ scan (Figure 13b), which is indicative of an interaction between $\mathrm{TiO}_{2}$ and silver. ${ }^{80}$ The combination of these results leads to the proposal of Scheme 1. In Scheme 1 it is proposed that $\mathrm{Ag}^{0}$ and $\mathrm{Ag}_{2} \mathrm{O}$ block the formation of the titanium formate bridge. The resulting titanium complex can then collapse readily upon calcination to form rutile.

Gaussian fits of the narrow scan Ti 2p XPS spectra (Supporting Information) of all samples before calcination reveals two signals. The intensity of the signals accordingly varies with the increasing presence of silver, further indicating that $\mathrm{Ag}^{0}$ \% $\mathrm{AgO}$ is interacting with titanium, ${ }^{81}$ thus facilitating the removal of formate species and allowing for the collapse of the $\mathrm{Ti}-\mathrm{O}$ 
Anatase to Rutile Transformation of $\mathrm{TiO}_{2}$

\section{SCHEME 1: Illustration of Blocking Mechanism of Silver on the Titanium Formate Bridge}

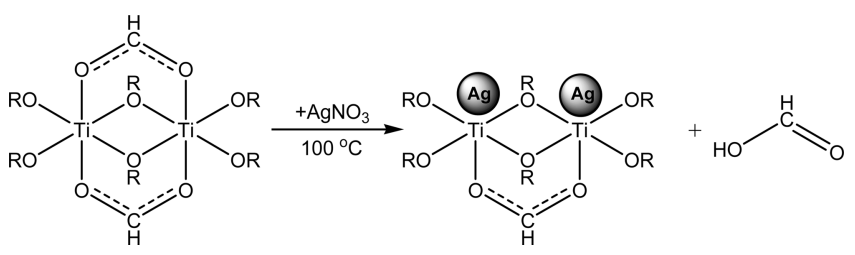

gel framework upon calcination to form rutile at lower temperatures.

Diffuse Reflectance Spectroscopy. To estimate the band gap distance, UV-vis spectroscopy was employed. The results show that silver does improve visible light absorbance of $\mathrm{TiO}_{2}$ due to silver plasmon absorption; moreover, a blue shift was observed for the band gap separation of the $\mathrm{TiO}_{2}$ materials upon increased silver addition.

Figure 14 shows the diffuse reflectance spectra for $0,1,3$, and $5 \mathrm{~mol} \% \mathrm{Ag} \mathrm{TiO}_{2}$. It can be seen that unmodified $\mathrm{TiO}_{2}$ has a smaller band gap than the silver modified $\mathrm{TiO}_{2}$. The blue shift of the silver modified materials can be attributed to the presence of additional silver. ${ }^{82}$

Figure 15 shows a diffuse reflectance spectrum of $\mathrm{Ag}$ nanoparticles where a strong absorbance is observed at $\sim 335$ $\mathrm{nm}$. The band gap of the $\mathrm{TiO}_{2}$ nanomaterials can therefore not be accurately determined because of the strong silver absorption. ${ }^{83}$ It is also clear that the presence of increased amounts of silver ( 3 and $5 \mathrm{~mol} \%$ ) facilitates visible light absorbance. This can also be seen from Figure 15 through strong visible light absorption of the silver nanoparticles. The proposed mechanism for the visible light absorbance of $\mathrm{Ag} \mathrm{TiO}_{2}$ is shown in Figure $16 .{ }^{80}$

It can also be seen in both Figures 14 and 17 that $3 \mathrm{~mol} \%$ silver $\mathrm{TiO}_{2}$ has greater absorption than $5 \mathrm{~mol} \% \mathrm{Ag}$ in the visible region. This is because increased levels of silver act as a physical block against $\mathrm{TiO}_{2}$ light absorption. This causes an increase in the diffuse light reflectance of the material. ${ }^{37}$

In Figure 18 it is observed that the band gap of the modified $\mathrm{TiO}_{2}$ is reduced, as seen by the red shift in the spectra of the 3 and $5 \mathrm{~mol} \% \mathrm{Ag} \mathrm{TiO}_{2}$ in comparison with Figures 14 and 17. This is attributed to the formation of rutile. Rutile has a smaller band gap than anatase $;^{13} \mathrm{XRD}$ results confirm that silver doped samples calcined at $800{ }^{\circ} \mathrm{C}$ have rutile structure (Figure 3). By

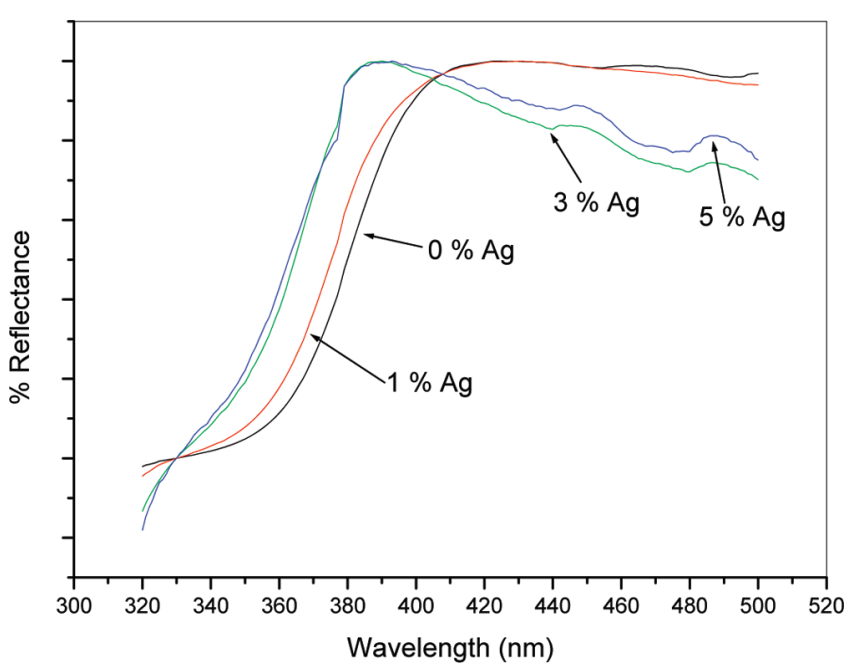

Figure 14. Diffuse reflectance spectra of $0,1,3$, and $5 \% \mathrm{Ag} \mathrm{TiO}_{2}$ calcined at $500{ }^{\circ} \mathrm{C}$.

J. Phys. Chem. C, Vol. $x x x$, No. $x x, X X X X \quad$ G

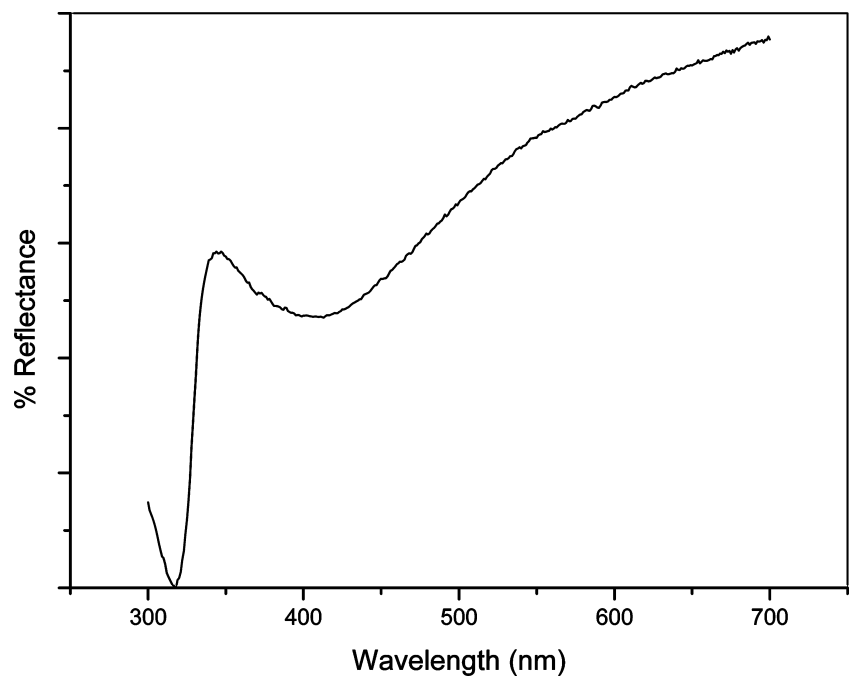

Figure 15. Diffuse reflectance spectrum of silver nanoparticles.

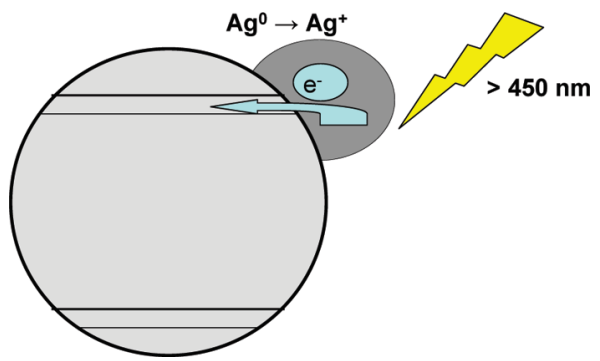

Figure 16. Mechanism for light absorption of silver.

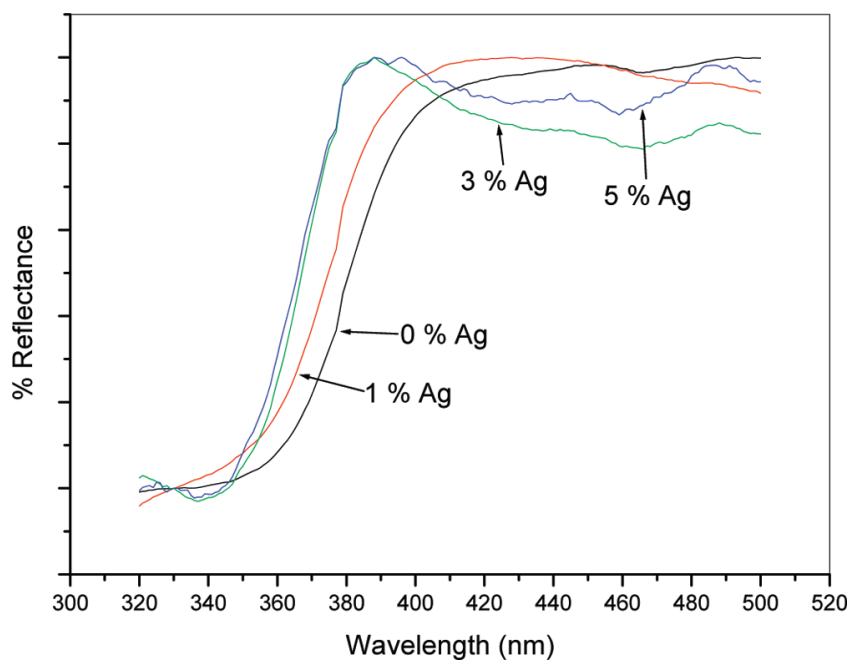

Figure 17. Diffuse reflectance spectra of $0,1,3$, and $5 \% \mathrm{Ag} \mathrm{TiO}_{2}$ calcined at $700{ }^{\circ} \mathrm{C}$.

comparison of Figure 18 with Figures 14 and 17, silver does not have the same influence in causing the blue shift. The mechanism of anatase to rutile transformation is one of nucleation and growth ${ }^{46,47}$ therefore, rutile particles are significantly larger than those of anatase. The larger particles may result in a significant reduction in the influence of silver on the band gap of the materials.

\section{Conclusions}

A systematic study of the effect of silver on the anatase to rutile transformation temperature of $\mathrm{TiO}_{2}$ has been carried out. By use of XRD, FTIR, Raman, DSC, and XPS it was proposed that the addition of silver blocks the formation of a titanium - 


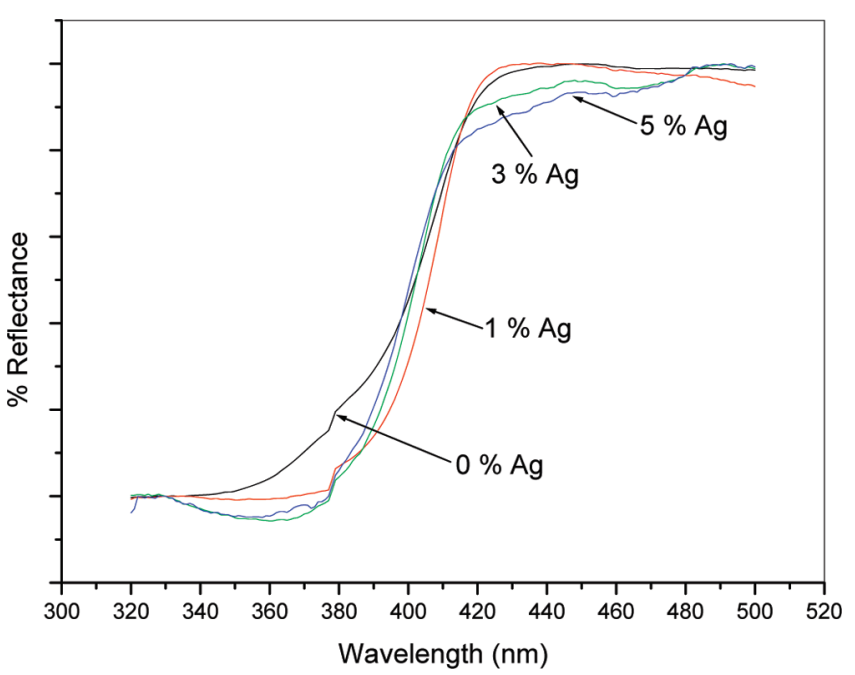

Figure 18. Diffuse reflectance spectra of $0,1,3$, and $5 \% \mathrm{Ag} \mathrm{TiO}_{2}$ calcined at $800{ }^{\circ} \mathrm{C}$.

445

446

447 carboxylate bridging ligand. This was clearly shown through the carboxylate stretches in FTIR, Raman and XPS. Without the formation of this bridging ligand the condensation pathway is altered, and the resulting titania polymer network is weakened. When calcined, this weakened structure can readily transform from anatase to rutile due to a greater atomic mobility. The sample with no silver present maintained anatase at greater temperatures than those that contained silver. This was due to the formation of a strong carboxylate bridge that promoted a more organized structure throughout the condensation process. The more ordered oligomer network of the sample without silver consisted of anatase at greater temperatures than those where silver was present. This was clearly seen from the XRD diffractograms. Previous reports have indicated that oxygen vacancies contribute to the early formation of rutile, but through XPS and PL, it was concluded that the presence of additional silver did not form extra oxygen vacancies. XPS also showed that $\mathrm{Ag}_{2} \mathrm{O}$ and $\mathrm{Ag}^{0}$ was present in the samples before high temperature calcination. It was also showed through XPS that there may be an interaction between $\mathrm{Ag}$ and $\mathrm{Ti}$, which agrees with the proposed mechanism outlined in Scheme 1.

PL studies showed that the addition of silver reduced recombination of electron, hole pairs, and PL spectra did not provide any evidence for the presence of additional oxygen vacancies with increased amounts of silver. Diffuse reflectance showed greater visible light absorbance through silver plasmon resonance.

An alternative mechanism has been proposed on how silver effects the anatase to rutile transition of $\mathrm{TiO}_{2}$. In the proposed mechanism, silver blocks the formation of a bridging ligand with the titanium alkoxide precursor. This is clearly shown in FTIR, Raman, and XPS spectra, and the resulting lower formation of rutile is clear from XRD and DSC.

Acknowledgment. The authors would like to thank the EPA for funding and DIT, focas, and CREST for materials and resources. The authors would also like to thank Aisling Kirwan for FESEM images. This paper is dedicated to Professor John M. Kelly, C. Chem. FRSC, on the occasion of completing 37 years of teaching and research at Trinity College Dublin, Ireland.

Supporting Information Available: Figures depicting Ti $2 p$ XPS spectrum of $0,1,3$, and $5 \% \mathrm{Ag}$ before calcination and $5 \%$ silver loading on $\mathrm{TiO}_{2}$ calcined at 700 and $800{ }^{\circ} \mathrm{C}$. This material is available free of charge via the Internet at http:// pubs.acs.org.

487 488

\section{References and Notes}

(1) Fox, M. A.; Dulay, M. T. Chem. Rev. 1993, 93, 341-357.

(2) Hoffmann, M. R.; Martin, S. T.; Choi, W.; Bahnemann, D. W. Chem. Rev. 1995, 95, 69-96.

(3) Honda, K.; Fujishima, A. Nature 1972, 238, 37.

(4) Liu, H.; Cheng, S.; Wu, M.; Zhang, J.; Li, W.; Cao, C. J. Phys. Chem. A 2000, 104, 7016 .

(5) Tada, H.; Yamamoto, M.; Ito, S. Langmuir 1999, 15, 3699.

(6) Xu, Y. M.; Langford, C. H. Langmuir 2001, 17, 897.

(7) Yu, J.; Yu, H.; Ao, C. H.; Lee, S. C.; Yu, J. C.; Ho, W. Thin Solid Films 2006, 496, 273-280.

(8) Yu, J. G.; Yu, H. G.; Cheng, B.; Zhao, X. J.; Yu, J. C.; Ho, W. K. J. Phys. Chem. B 2003, 107, 13871.

(9) Yu, J. G.; Yu, J. G.; Ho, W. K.; Zhang, L. Z. Chem. Commun. 2001, 1942.

(10) Zhao, J.; Wu, T.; Wu, K.; Oikawa, K.; Hidaka, H.; Serpone, N. Environ. Sci. Technol. 1998, 32, 2394-2400.

(11) Hu, Y.; Tsai, H.-L.; Huangk, C.-L. Eur. Ceram. Soc. 2003, 23, 691-696.

(12) Shao, Y.; Tang, D.; Sun, J.; Lee, Y.; Xiong, W. China Particuology 2004, 2, 119-123.

(13) Carp, O.; Huisman, C. L.; Reller, A. Prog. Solid State Chem. 2004, 32, 33-177.

(14) Aguado, J.; van Grieken, R.; Lopez-Munoz, M. J.; Marugan, J. Catal. Today 2002, 75, 95-102.

(15) Diebold, U. Surf. Sci. Reports 2003, 48, 53-229.

(16) Kuo, Y.-L.; Chen, H.-W.; Ku, Y. Thin Solid Films 2006, 515, 34613468 .

(17) Hamal, D. B.; Klabunde, K. J. J. Colloid Interface Sci. 2007, 311, $514-522$.

(18) Luo, H.; Takata, T.; Lee, Y.; Zhao, J.; Domen, K.; Yan, Y. Chem. Mater. 2004, 16, 846-849.

(19) Asahi, R.; Morikawa, T.; Oikawa, K.; Aoki, K.; Taga, Y. Science 2001, 293, 269.

(20) Ihara, T.; Miyoshi, M.; Iriyama, Y.; Matsumoto, O.; Sugihara, S. Appl. Catal. B 2003, 42, 403-409.

(21) Martyanov, I. N.; Uma, S.; Rodrigues, S.; Klabunde, K. J. Chem. Commun. 2004, 2476-2477.

(22) Umebayashi, T.; Yamaki, T.; Itoh, H.; Asai, K. Appl. Phys. Lett. 2002, 81, 454-456.

(23) Khan, S. U. M.; Al-Shahry, M.; Ingler, W. B. Science 2002, 297, 2243-2245.

(24) Hong, X.; Wang, Z.; Cai, W.; Lu, F.; Zhang, J.; Yang, Y.; Ma, N.; Liu, Y. Chem. Mater. 2005, 17, 1548-1552.

(25) Choi, W.; Termin, A.; Hoffmann, M. R. J. Phys. Chem. 1994, 98. (26) Nagaveni, K.; Hegde, M. S.; Madras, G. J. Phys. Chem. B 2004, 108.

(27) Wang, W.; Zhang, J.; Chen, F.; He, D.; Anpo, M. J. Colloid Interface Sci. 2008, 323, 182-186.

(28) Zhu, J.; Chen, F.; Zhang, J.; Chen, H.; Anpo, M. J. Mol. Catal. A 2004, 216.

(29) Zhu, J.; Deng, Z.; Chen, F.; Zhang, J.; Chen, H.; Anpo, M.; Huang,

J.; Zhang, L. Appl. Catal. B 2006, 62.

(30) Demeestre, K.; Dewulf, J.; Ohno, T.; Salgado, P. H.; Langenhove, H. V. Appl. Catal. B 2005, 61, 140.

(31) Behar, D.; Rabani, J. J. Phys. Chem. B 2006, 110, 8750.

(32) Kim, S. K.; Hwang, S. J.; Choi, W. Sci. Technol. 2005, 35, 2381.

(33) Li, X. Z.; Li, F. B. Environ. Sci. Technol. 2001, 35, 2381.

(34) You, X.; Chen, F.; Zhang, J.; Anpo, M. Catal. Lett. 2005, 102, 247.

(35) Chao, H. E.; Yun, Y. U.; Xingfang, H. U.; Larbot, A. ECERS 2003, 23, 1457-1464.

(36) Kuo, Y.-L.; Chen, H.-W.; Ku, Y. Thin Solid Films 2007, 515, 34613468

(37) Seery, M. K.; George, R.; Floris, P.; Pillai, S. C. J. Photochem. Photobiol. A 2007, 189, 258-263.

(38) Choi, H.; Stathatos, E.; Dionysiou, D. D. Top. Catal. 2007, 44, $513-521$.

(39) Livage, J.; Sanchez, C.; Henry, M.; Doeuff, S. Solid State Ionics 1989, 32/33, 633-638.

(40) Nolan, N. T.; Seery, M. K.; Pillai, S. C. J. Phys. Chem. C 2009, 113, 16151-16157.

(41) Pillai, S. C.; Periyat, P.; George, R.; McCormack, D. E.; Seery, M. K.; Hayden, H.; Colreavy, J.; Corr, D.; Hinder, S. J. J. Phys. Chem. C 2007, 111, 1605-1611.

(42) Periyat, P.; Pillai, S. C.; McCormack, D. E.; Colreavy, J.; Hinder, S. J. J. Phys. Chem. C 2008, 112, 7644-7652

(43) Periyat, P.; McCormack, D. E.; Hinder, S. J.; Pillai, S. C. J. Phys. Chem. C 2009, 113, 3246-3253. 
Anatase to Rutile Transformation of $\mathrm{TiO}_{2}$

(44) Spurr, R.; Myers, H. Anal. Chem. 1957, 29, 760.

(45) Oliveri, G.; Ramis, G.; Busca, G.; Sanchez Escribano, V. J. Mater Chem. 1993, 3, 1239-1249.

(46) Ding, X.-Z.; Liu, X.-H. J. Mater. Res. 1998, 13, 2556-2559.

(47) Gribb, A. A.; Banfield, J. F. Am. Mineral. 1977, 82, 717-728.

(48) Zhang, H.; Banfield, J. F. J. Mater. Res. 2000, 15, 437-448.

(49) Ahn, Y. U.; Kim, E. J.; Kim, H. T.; Hahn, S. H. Mater. Lett. 2003, 57, 4660-4666.

(50) Hishita, S.; Mutoh, I.; Koumoto, K.; Yanagida, H. Ceram. Intern. 1982, 9, 61-67.

(51) MacKenzie, K. J. D. J. Brit. Ceram. Soc. 1975, 74, 77-84.

(52) Epifani, M.; Giannini, C.; Tapfer, L.; Vasanelli, L. J. Am. Ceram. Soc. 2000, 85, 2385-2393.

(53) Litter, M. I. Appl. Catal. B 1999, 23, 89-114.

(54) Brinker, C. J.; Scherer, G. W. The Physics and Chemistry of SolGel Science; Academic Press: New York, 1990.

(55) Nakamoto, K. Infrared and Raman Spectra of Inorganic and Coordinated Compounds; John Wiley: New York, 1997.

(56) Nguyen, T.-V.; Choi, D.-J.; Yang, O.-B. Res. Chem. Intermed. 2005 $31,483-491$.

(57) Hwang, D. S.; Lee, N. H.; Lee, D. Y.; Song, J. S.; Shin, S. H.; Kim, S. J. Smart Mat. Struct. 2006, 15, S74-S80.

(58) Kittaka, S.; K., M.; Takahara, S. J. Solid State Chem. 1997, 132, $447-450$.

(59) Yoshitake, H.; Abe, D. Microporous Mesoporous Mater. 2009, 119, $267-275$.

(60) Guilment, J.; Pencelot, O.; Rigola, J.; Truchet, S. Vib. Spectrosc. 1996, 11, 37-49.

(61) Phule, P. P.; Risbud, S. H. J. Mater. Sci. 1990, 25, 1169-1183.

(62) Sanchez, C.; Livage, J.; Henry, M.; Babonneau, F. J. Non-Cryst. Solids 1988, 100, 65-76.

(63) Takahaschi, Y.; Kiwa, K.; Kobayashi, K.; Matsuki, M. J. Am. Ceram. Soc. 1991, 74, 67-71.

(64) Takahaschi, Y.; Matsuoka, Y. J. Mater. Sci. 1988, 23, 2259-2266.

(65) Czakis-Sulikowska, D.; Czylkowska, A.; Malinowska, A. J. Therm. Anal. Cal. 2002, 67, 667-668.
J. Phys. Chem. C, Vol. xxx, No. xx, XXXX I

(66) Deacon, G. B.; Phillip, R. J. Coord. Chem. Rev. 1980, 33, 227250.

(67) Lewandowski, W.; Fuks, L.; Lewandowski, H. J. Inorg. Biochem. 2005, 99, 1407-1423.

(68) Manhas, B. S.; Trikha, A. K. J. Indian Chem. Soc. 1982, 59, 315 319.

(69) Kung, H. H.; Ko, E. I. Chem. Eng. J. 1996, 64, 203-214.

(70) Suresh, C.; Biju, V.; Mukundan, P.; Warrier, K. G. K. Polyhedron 1998, 17, 3131-3135.

(71) Ben Amor, S.; Baud, G.; Jacquet, M.; Nanse, G.; Fioux, P.; Nardin, M. Appl. Surf. Sci. 2000, 153, 172-183.

(72) Korosi, L.; Papp, S.; Menesi, J.; Illes, E.; Zollmer, V.; Richardt, A.; Dekany, I. Colloids Surf. A 2008, 319, 136-142.

(73) Xu, W.-X.; Zhu, S.; Fu, X.-C. Appl. Surf. Sci. 1998, 136, 194205.

(74) Barlier, V.; Bounor-Legare, V.; Boiteux, G.; Davenas, J.; Leonard, D. Appl. Surf. Sci. 2008, 254, 5408-5412.

(75) Henderson, M. A. Surf. Sci. 1999, 419, 174-187.

(76) Hoflund, G. F.; Yin, H. L.; Grogan, A. L., Jr.; Asbury, D. A. Langmuir 1988, 4, 346-350.

(77) Xu, J.; Chang, Y.; Zhang, Y.; Ma, S.; Qu, Y.; Xu, C. Appl. Surf. Sci. 2008, 255, 1996-1999.

(78) Akyol, A.; Yatmaz, H. C.; Bayramoglu, M. Appl. Catal. B 2004, $54,19-24$.

(79) Liqiang, J.; Yichun, Q.; Baiqi, W.; Shudan, L.; Baojiang, J.; Libin, Y.; Wei, F.; Honggang, F.; Jiazhong, S. Solar Energy Mater. Solar Cells 2006, 90, 1773-1787.

(80) Gunawan, C.; Teoh, W. Y.; Marquis, C. P.; Lifia, J.; Amal, R. Small $2009,5,341-344$

(81) Spojakina, A.; Kraleva, E.; Jiratova, K.; Petrov, L. Appl. Catal. A 2005, 288, 10-17.

(82) He, C.; Xiong, Y.; Chen, J.; Zha, C.; Zhu, X. J. Photochem. Photobiol. A 2003, 157, 71-79.

(83) Sen, S.; Mahanty, S.; Roy, S.; Heintz, O.; Bourgeois, S.; Chaumont, D. Thin Solid Films 2005, 474, 245-249.

JP1016054
604 605

606 607 608 610 611 612 613 614 615 616 617 618 619 620 621 622 623 